\title{
Cost-effectiveness and cost-utility of a Web-based or print-delivered tailored intervention to promote physical activity among adults aged over fifty: an economic evaluation of the Active Plus intervention
}

Rianne HJ Golsteijn ${ }^{1 *}$, Denise A Peels ${ }^{1}$, Silvia MAA Evers ${ }^{2,3,4}$, Catherine Bolman ${ }^{1}$, Aart N Mudde ${ }^{1}$, Hein de Vries ${ }^{2,5}$ and Lilian Lechner ${ }^{1}$

\begin{abstract}
Background: The adverse health effects of insufficient physical activity (PA) result in high costs to society. The economic burden of insufficient PA, which increases in our aging population, stresses the urgency for cost-effective interventions to promote PA among older adults. The current study provides insight in the cost-effectiveness and cost-utility of different versions of a tailored PA intervention (Active Plus) among adults aged over fifty.

Methods: The intervention conditions (i.e. print-delivered basic ( $P B ; N=439$ ), print-delivered environmental ( $P E ; N=435)$, Web-based basic ( $W B ; N=423)$, Web-based environmental $(W E ; N=432)$ ) and a waiting-list control group were studied in a clustered randomized controlled trial. Intervention costs were registered during the trial. Health care costs, participant costs and productivity losses were identified and compared with the intervention effects on PA (in MET-hours per week) and quality-adjusted life years (QALYS) 12 months after the start of the intervention. Cost-effectiveness ratios (ICERs) and cost-utility ratios (ICURs) were calculated per intervention condition. Non-parametric bootstrapping techniques and sensitivity analyses were performed to account for uncertainty.

Results: As a whole (i.e. the four intervention conditions together) the Active Plus intervention was found to be cost-effective. The PB-intervention (ICER $=€-55 / M E T$-hour), PE-intervention (ICER $=€-94 / M E T-h o u r)$ and the WE-intervention (ICER $=€-139 / M E T-h o u r)$ all resulted in higher effects on PA and lower societal costs than the control group. With regard to QALYs, the PB-intervention (ICUR $=€ 38,120 / \mathrm{QALY}$ ), the PE-intervention (ICUR = $€ 405,892 / \mathrm{QALY}$ ) and the WE-intervention (ICUR $=€-47,293 /$ QALY) were found to be cost-effective when considering a willingness-to-pay threshold of $€ 20,000 /$ QALY. In most cases PE had the highest probability to be cost-effective.

Conclusions: The Active Plus intervention was found to be a cost-effective manner to increase PA in a population aged over fifty when compared to no-intervention. The tailored Active Plus intervention delivered through printed material and with additional environmental information (PE) turned out to be the most cost-effective intervention condition as confirmed by the different sensitivity analyses. By increasing PA at relatively low costs, the Active Plus intervention can contribute to a better public health.
\end{abstract}

Trial registration: Dutch Trial Register: NTR2297

Keywords: Tailored intervention, Older adults, Physical activity, Cost-effectiveness, Cost-utility, Quality of life

\footnotetext{
* Correspondence: Rianne.Golsteijn@ou.nl

'Department of Psychology and Educational Sciences, Open University of the Netherlands, Heerlen, PO Box 2960, 6401 DL Heerlen, The Netherlands

Full list of author information is available at the end of the article
} 


\section{Background}

Lack of physical activity (PA) is a problem in many developed countries, as almost half of the population does not meet the recommended PA guideline (i.e. being physically active at least 5 days a week, 30 minutes a day with moderate to vigorous intensity) [1,2]. Insufficient PA is a major risk factor for a number of chronic diseases, such as coronary heart disease, stroke, cancer and type 2 diabetes [3]. The World Health Organization estimated that about $3.5 \%$ of the total disease burden and $10 \%$ of deaths in Europe can be attributed to a lack of PA [4]. The adverse health effects of insufficient PA result in high costs to society in the form of health care costs, productivity losses and costs associated with premature death [3]. Although it is difficult to determine the total cost of insufficient PA on society, as only a fraction of the costs can be estimated [4,5], some estimations have been made. Oldridge [6] mentions that a lack of PA contributes to between $1.5 \%$ and $3.0 \%$ of direct health care costs in developed countries. Colman and Walker [7] estimated that in a population of 10 million people, where half of the population is too inactive to enjoy health benefits from PA, the costs of insufficient PA can be up to $€ 910$ million a year [7]. This burden to society emphasizes the importance of stimulating people to become more physically active, which can result in better public health and thereby reduce health care costs $[5,8,9]$.

Sufficient PA is particularly important for older adults as it enables them to maintain their mobility and independence, to improve their muscle strength, cognitive functioning and mental and emotional well-being, and to prevent falls and chronic diseases [10,11]; additional benefits can be achieved if those who are already physically active further increase their PA [12]. The expectation that the proportion of elderly in Western countries increases (e.g., from $15 \%$ in 2010 to nearly $26 \%$ in 2040 in the Netherlands [13]), stresses the urgency for cost-effective interventions aimed at promoting PA for older adults. Research has shown that improvements in PA result in savings in health care costs, even within a year [14].

Computer-tailoring has proven to be an effective intervention strategy for promoting PA behavior [15-19]. It is a potentially cost-effective strategy, as it provides the opportunity to give an individual advice to large populations with minimal costs. Several studies have shown that interventions aimed at personal characteristics of participants and interventions using behavioral change strategies (as applied in most tailoring interventions) are most effective in stimulating PA [16]. As a consequence, a computer-tailored intervention to stimulate PA among adults aged over fifty, the Active Plus intervention, was developed and evaluated on effectiveness. This theorydriven, evidence-based intervention is available in four conditions: (1) a basic print-delivered condition (targeting socio-cognitive determinants of PA); (2) an environmental print-delivered intervention (targeting environmental determinants in addition to the basic intervention); (3) a basic Web-based condition; and (4) an environmental Web-based condition [20,21]. The different intervention conditions resulted in different effects on long-term PA behavior; the printed conditions resulted in higher effects than the Web-based conditions [17]. Intervention costs are expected to differ between the different intervention conditions as well; the Web-based conditions are expected to have lower intervention costs than the printed intervention conditions, and additional intervention costs can be expected as a result of providing environmental information. Cost-effectiveness analyses may inform us of which intervention condition effects and costs are optimal.

Until now, in general but also specifically for older adults, very little research has been done to compare the cost-effectiveness of internet-based computer-tailored PA interventions with other PA interventions [2,22,23]. One study by Lewis et al. [24] has shown that an internetbased intervention was cheaper than a print-delivered intervention, however this study did not provide insight in the effects of those interventions. Two other studies comparing print-delivered computer-tailored interventions with phone-delivered computer tailored interventions $[18,25]$, found the print-delivered interventions to be more cost-effective. However, none of these three studies adopted a societal perspective, which is needed to get a complete description of costs and benefits [26]. The Dutch guidelines for economic evaluations also recommend a societal perspective [27]. A societal perspective is the broadest possible perspective, and includes all relevant costs and effects to society (i.e., intervention costs, health care costs, participant and family costs and productivity losses). The absence of this perspective hampers the interpretation of the results of the studies for policy goals.

The purpose of the current study is to evaluate the four Active Plus intervention conditions in terms of costs and effects from a societal perspective. In addition to reporting effects on PA behavior, the results are also presented in terms of Quality Adjusted Life Years (QALYs), enabling policy makers to prioritise between different kinds of interventions in different areas (e.g. comparing the cost-effectiveness of a smoking cessation intervention with a PA intervention).

\section{Methods}

This study is approved by the Medical Ethics Committee of Atrium - Orbis - Zuyd (10-N-36) and was registered in the Dutch Trial Register (NTR 2297).

\section{Study design and participants}

The four Active Plus intervention conditions (i.e. printed basic (PB), printed environmental (PE), Web-based basic 
(WB), Web-based environmental (WE)) and a waiting-list control group $(C)$ were studied in a clustered randomised controlled trial. In order to prevent subjects from different intervention conditions contaminating each other, the intervention conditions were randomly assigned to different but comparable municipal health council (MHC) regions. After randomisation, for each intervention condition 14 (matched) neighbourhoods within the MHC region were selected. The neighbourhoods were matched on their urban character (i.e. the number of addresses per $\mathrm{km}^{2}$ ), percentage of people with a low SES, percentage of people with a high SES, and the percentage of people over 50 years of age. A sample of eligible participants from each MHC region received an invitation to participate in the study. For the print-delivered conditions (PB $N=2,380 ; \operatorname{PE} N=2,268$ ) this invitation contained an information letter, a questionnaire, a prepaid return envelope, and an informed consent form; the invitation for the Web-based conditions contained an information letter, additional information about how to complete the online questionnaires, a hyperlink to the Active Plus website, and a personal username and password to log in to the website. To reach equal participation rates in the Web-based conditions, a larger sample received an invitation to participate (WB $N=2,847$; WE $N=4,321$ ). For the waiting-list control group $(N=1,850)$ the invitation contained an information letter, a questionnaire, a prepaid return envelope, and an informed consent form. The information letter told the participant that they were invited to complete 4 questionnaires about PA during the upcoming year and that they would receive a PA advice after one year as a reward for their cooperation. The participant flow through the study is graphically depicted in Figure 1. More detailed information about the recruitment of participants and the power calculation can be found elsewhere [28].

There were four evaluation assessments: (1) at the start (T0: also providing data for the first and second tailored advice); (2) three months after baseline (T1: also providing data for the third tailored advice); (3) six months after baseline (T2); and (4) twelve months after baseline (T3). Questions for the economic evaluation were included at baseline, six-, and twelve months.

\section{Intervention}

The Active Plus intervention is a computer-tailored, theory and evidence-based intervention to stimulate or maintain PA among people aged over fifty [20]. During the intervention, participants received a tailored PA advice at three moments based on their personal characteristics, motivational readiness for behaviour change, and needs assessed by previous questionnaires. Psychosocial determinants such as awareness, attitude, self-efficacy, motivation, action planning and coping planning were addressed in the tailored advice. Participants received their first advice within two weeks after completing the baseline questionnaire. The second advice was provided two months after completing the baseline questionnaire. The third advice was provided within four months after baseline measurement, after completing the second questionnaire, enabling us to provide respondents with ipsative feedback about changes in their PA behaviour and the psychosocial determinants in the previous 4 months. This means that improvements in (determinants of) PA were rewarded and possible relapses were addressed appropriately with additional suggestions to increase PA levels again. The intervention was delivered in a printed and a Web-based condition [21] and in a condition with and a condition without additional environmental components (e.g., walking and cycling routes and PA possibilities and initiatives in participants own neighbourhood and home exercises) [29]. Participants in the printed conditions received their advice by mail, whereas participants in the Web-based conditions received their advice through a website and by email. Each tailored advice contained between five and 11 pages of text and illustrations. The specific content of the intervention has been described extensively elsewhere [30].

\section{Measurements \\ Identification of costs and effects}

An economic evaluation was performed from a societal perspective including all relevant costs to society, therefore intervention costs, health care costs, participant and family costs and productivity losses were identified as relevant costs. Intervention costs relevant for implementation of the intervention included invitation costs, printing and postage costs, staffing costs for handling questionnaires (which are part of the intervention), advice and reminders, and gathering environmental information, and hosting costs for the tailoring software and website. Response rates are incorporated in the invitation costs (e.g., to include one participant, an information package has to be send out to at least four potential participants). Intervention costs are specified in more detail in Additional file 1. Costs and time attributable to the research (e.g. printing and postage costs for the research part of the questionnaires) and the development of the intervention were excluded, as these costs will not have to be paid in future implementation.

Based on discussion with experts regarding economic evaluations, previous research and economic evaluation literature [27,31-34], the following health care costs were assumed to be relevant: costs related to consultation of a general practitioner, lifestyle coach (i.e., dietician, PA advisor), paramedical care provider (e.g. physiotherapist), mental health care provider, company doctor, social worker, practice nurse, medical specialist, or any remaining health care providers. Furthermore, hospital admission and surgery costs were identified as relevant costs, as well as 


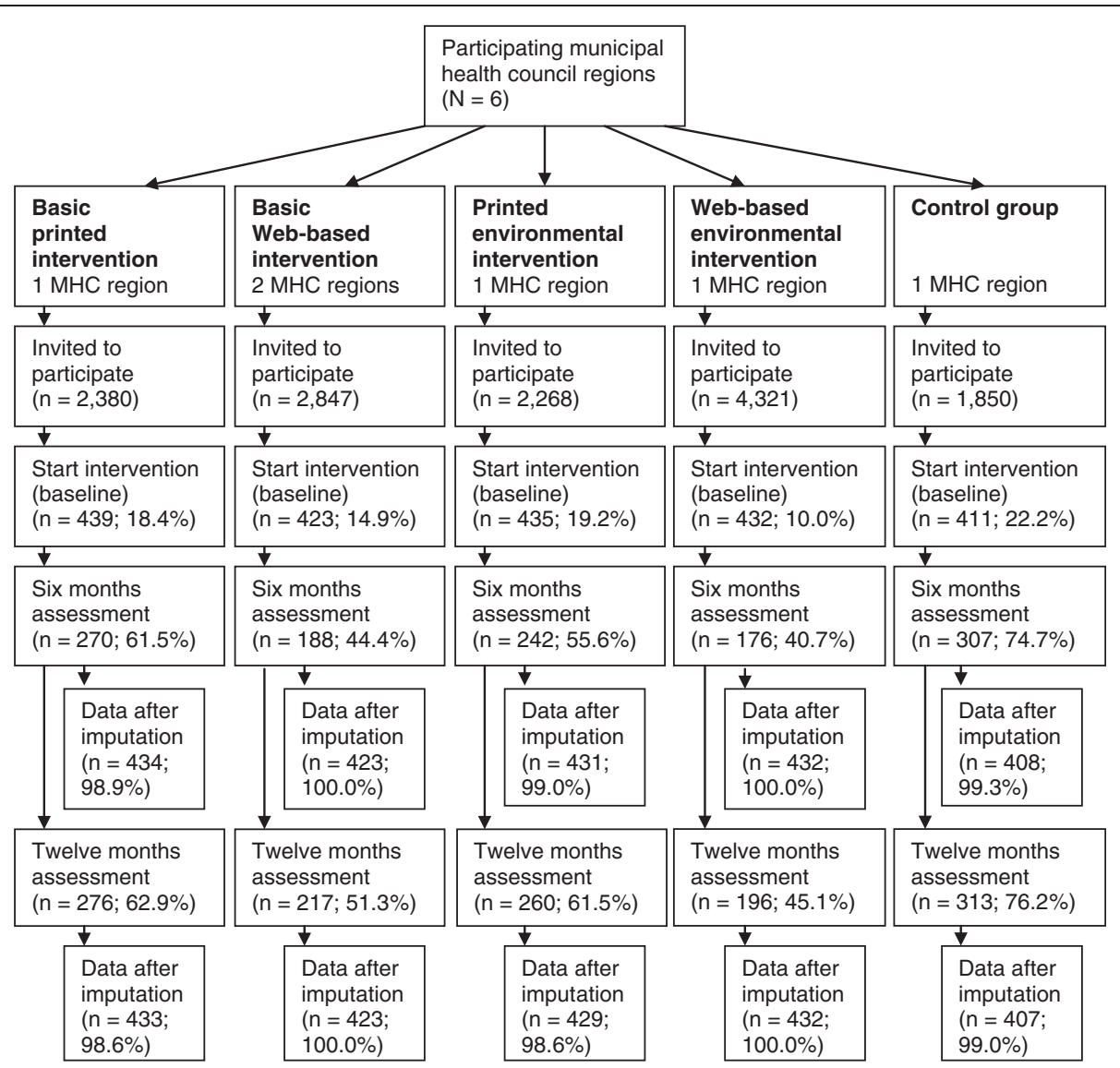

Figure 1 Participant flow through the Active Plus intervention Note: Percentages of the 6 and 12 months assessment are reported in contrast to the number of baseline participants.

prescribed and over-the-counter medication and paid homecare. Participant and family costs consisted of costs incurred for being physically active (i.e., buying sports products and paying membership fees for sports club or gym), travel costs to health care providers and unpaid homecare. Time costs for participating in the intervention were assumed to occur in leisure time and were expected to be reflected in the quality of life of the participants and therefore, were not expressed in monetary value, according to the Dutch guidelines [27]. Productivity losses were considered as relevant costs, since a substantial part of the participants was expected to have a paid job, especially in the younger age group.

Intervention effects were expressed in MET-hours per week and QALYs. MET stands for Metabolic Equivalents and presents the amount of energy expended on PA as a multiple of the energy expended while seated at rest. Combining both the duration (hours) and the intensity (MET rate) of PA results in the measure MET-hours of PA. A QALY is a measure of the additional life expectancy resulting from an intervention, corrected for the quality of that life expectancy. A year in perfect health results in a QALY of 1, whereas death results in a QALY of 0 . Some health states are valued as being worse than dead and therefore a QALY score can also be negative [33].

\section{Measurement of costs and effects}

Cost invested and time needed for the implementation of the intervention were registered in detail during the research. Health care costs, participant and family costs and productivity losses were assessed 3 months retrospectively (for medical specialist care and hospital admission 6 months) with a costing questionnaire. For health care costs, participants were asked to indicate, if applicable, which health care provider they attended and how often, how many nights they stayed in the hospital, which surgery they had, which medication they used and if they received any paid home care. To estimate participant and family costs, questions were included about the money participants spend to pay for their membership at sport accommodations and which sports equipment they bought and to assess if participants received any unpaid home care. Travel costs to health care providers were based on average travel distances and parking fees as described by Hakkaart - van Roijen et al. [27]. Absence from a paid job due to illness (hours in the preceding 
3 months) was assessed to calculate productivity losses. Cost questionnaires used in previous research were reviewed and adapted to capture the most important information for the current study [35].

The primary outcome measure for the cost-effectiveness analysis was PA expressed in MET-hours per week, assessed with the validated self-administered Dutch Short Questionnaire to Assess Health Enhancing Physical Activity (SQUASH) which has a reasonable reproducibility $\left(\mathrm{r}_{\text {spearman }}=0.58 ; 95 \% \mathrm{CI}=0.36-0.74\right)$ and relative validity $\left(r_{\text {spearman }}=0.45 ; 95 \% \mathrm{CI}=0.17-0.66\right) \quad$ [36]. A study of Wagenmakers et al. [37] showed that using the SQUASH in an older population can be considered as a fairly reliable tool as well $\left(\mathrm{r}_{\text {spearman }}=0.57\right)$ and that the validity (varying between 0.20 and 0.67 when compared with the Actigraph) was comparable to those of other questionnaires.

Quality of life, in terms of QALYs, was assessed using the EuroQol (EQ-5D-3L) [38], as is currently recommended by the National Institute for Health and Clinical Excellence (NICE) as measure for assessing quality of life [39]. The EQ-5D-3L is frequently used in economic evaluations of preventive and Web-based interventions [31,40-42].

\section{Valuation of costs and effects}

For the valuation of health care costs and patient and family costs, cost prices of the updated Dutch manual for cost analysis in health care research were used [27]. If available, standardised cost prices were used; if unavailable, real costs or average tariffs were used. According to the guidelines, costs of medications were calculated based on defined daily dosages and included 6\% Value Added Tax, prescription charges and claw-back, a lawful discount percentage to be subtracted from medication prices by pharmacists [27,43]. Costs spent on sports membership fees and sports equipment were valued based upon the cost prices specified by the participants. For this category, outliers (i.e., participants indicating that they purchased a swimming pool or soccer stadium) were excluded. Prices for unpaid home care were based on shadow prices for domestic care [27]. Travel costs were calculated based on the number of visits to a health care provider, the average travel distances and cost prices and parking fees as described in the Dutch manual for cost analysis [27]. Productivity losses for paid work were valued according to mean salaries (differentiated for men and women) and the friction cost method [27]. For some costs items, valuation was difficult as respondents were not specific in their description thus, making valuation impossible (i.e., just mentioning surgery without any further specification). These costs were not valued, but regarded as intangible costs.

For the effects, weekly MET-hours of PA per week were calculated. QALYS were calculated based on participants' answers on the five dimensions of the EuroQol (EQ-5D-3L)
[38]: mobility, self-care, daily activities, pain/discomfort and depression/anxiety. Each dimension was rated on three levels: no complaints, some complaints and many complaints. The five dimensions were combined into a health state and subsequently, utility values were calculated using preferences elicited from a general Dutch population [40]. An overall QALY score was calculated by multiplying the duration of a health state by the quality weight for the health status (utility score) using all measurements [33]. This indicates that for a perfect health state within one year, a maximum QALY score of 1.0 can be obtained. Consequently, at 6 months follow-up a maximum QALY score of 0.5 can be obtained.

\section{Statistical analyses}

Annual costs were calculated by adding up the costs from the 6-month measurement and the 12-month measurement. However, health care costs and membership fees for sports facilities were assessed 3 months retrospectively, therefore these costs were extrapolated to a period of 6 months in order to have an equal measurement period. Costs for buying sports equipment were assumed to occur less frequently and therefore costs occurring within 3 months were adopted as costs occurring in 6 months. All cost prices were indexed to 2011 costs using the consumer price index of the Netherlands Central Institute for Statistics [44]. Since the time frame in which costs and effects occurred was relatively short (one year for the individual participant), discounting was not necessary [33].

Missing data in cost outcomes and quality of life outcomes were imputed with longitudinal imputation techniques. Missing data on 6 months follow-up were imputed by linear interpolation (i.e., imputation with participants' mean on the previous and next measurement), whereas the missing data on 12 months were replaced based on the principle of last observation carried forward (LOCF) [33]. Due to seasonal influences, linear interpolation and LOCF were not possible for the physical activity outcomes. Missing data on 6 months were, if available, imputed with the 12-month outcomes, which is a relatively conservative assumption since the effects after 12 months were substantially less than the effects after 6 months. If the 12-month outcomes were not available, the effect of the control group (from similar age and gender subgroups) was applied. Missing data on 12 months were also imputed with the effect of the control group. This is also a relatively conservative assumption, since these persons may have participated in the full intervention.

One-way analyses of variance (ANOVA) with Tukey's post hoc tests and Chi-square tests were conducted to assess baseline differences between the four intervention conditions and the control group in demographics, PA and utility. Due to the skewed nature of cost data, baseline costs were compared using non-parametric bootstrapping 
based on repeated sampling (5,000 times) from the observed data, with $95 \%$ confidence intervals $(95 \% \mathrm{CI})$ in percentiles [32]. Correction for baseline differences has not often been applied in economic evaluation as most techniques for baseline correction do not result in patient level corrections, which are necessary for the application of bootstrap techniques and constructing cost-effectiveness acceptability curves [45]. There are only some experimental techniques available to correct for baseline differences [45], therefore we only corrected for baseline differences in the sensitivity analyses.

Mean effects 12 months after the intervention started were analysed using ANOVA's with Tukey's post hoc tests and Chi-square tests. A total of 27 participants were excluded from further analyses due to missing outcome measures or being an outlier according to the guidelines of the SQUASH (i.e., reporting PA levels of more than 6,720 minutes per week) [36]. Cost data were compared with non-parametric bootstrapping as described above. Comparisons were made between the control group and each intervention condition. Both printed interventions were compared to both Web-based interventions (PB vs. WB; PE vs. WE) and both basic interventions were compared to both interventions with additional environmental information (PB vs. PE; WB vs. WE).

Incremental cost-effectiveness ratios (ICER) and incremental cost-utility ratios (ICUR) were calculated by dividing the difference in costs by the difference in effects (PA in MET-hours and in QALYs) between the control group and the intervention group as a whole (i.e., the four intervention conditions together), to assess the cost-effectiveness and cost utility of the Active Plus intervention against usual care. Furthermore, comparisons were made between the separate intervention conditions to gain insight into which intervention condition is preferred from a cost-effectiveness perspective. If an intervention condition results in higher effects with lower costs, the intervention is preferred (dominant); an intervention condition with lower effects against higher costs is not preferred (dominated). In case of higher effects and higher costs, or lower effects and lower costs, the preference for an intervention condition depends on how much society is willing to pay for a certain gain in effect. Currently there is no fixed willingness-to-pay (WTP) threshold in the Netherlands and it can be up to $€ 80,000$, depending on the disease burden [46]. As it is expected that the disease burden of insufficient PA is relatively low, we used a maximum WTP of $€ 20,000 /$ QALY, which is often used for preventive interventions $[46,47]$. For PA outcomes no maximum WTP is yet defined.

To assess uncertainty around the ICERs, cost and effect pairs were bootstrapped (1,000 bootstrap replications with a WTP threshold of $€ 20,000)$. Results of the bootstrap analyses were graphically depicted in a cost-effectiveness acceptability curve (CEAC) presenting the probability of the Active Plus intervention being cost-effective compared to the control group for a range of WTP threshold values. CEACs were also constructed for the different intervention conditions thus, indicating the probability of the intervention conditions to be more cost-effective than the others for a range of WTP thresholds. Based on the CEACs, cost-effectiveness frontiers (CEAF) can be defined, representing which intervention condition has the highest probability of net monetary benefit (NMB) for a range of WTP threshold values. A NMB can be calculated by valuing the difference in effect against the WTP for that effect (in this study $€ 20,000$ as specified above) [33].

To deal with uncertainty of parameter estimates, some sensitivity analyses were performed considering the different intervention conditions. The first sensitivity analysis was performed considering outcomes at 6 months followup (instead of 12 months follow-up) to gain insight into the cost-effectiveness shortly after ending the intervention, as this would provide insight into the cost-effectiveness when maintenance of the intervention effects was optimised. A second sensitivity analysis was performed with only the participants that reported both costs and effects, i.e., a complete cases analysis. Third, because analysis of baseline cost data showed statistical cost differences between the intervention groups, costs were corrected using a regression correction using the method described by Van Asselt et al. [45]. Age and sex were applied as covariates in this correction. Fourth, an analysis was performed from a health care perspective, only including health care costs, to gain more insight into the costeffectiveness for the health care setting. The fifth, sixth and seventh sensitivity analyses considered different outcome measures for PA and quality of life: minutes of moderate to vigorous PA per week, days per week with at least 30 minutes PA and utility values calculated using preferences from a general UK population [48]. Furthermore, to increase power and to make some inferences about the preferred delivery method and the inclusion of environmental information, sensitivity analyses (for MET-hours of PA and QALYs) were performed combining several intervention conditions. For the delivery method, both printed (PB and PE) and both online (WB and WE) conditions were taken together and compared to the control condition. With regard to providing environmental information, both basic (PB and $\mathrm{WB}$ ) and both environmental (PE and WE) conditions were taken together and compared to the control condition.

\section{Results}

\section{Baseline characteristics}

In total 2,140 participants were recruited into the study (see Figure 1). Baseline characteristics of the study population are shown in Table 1. Significant baseline differences 
Table 1 Baseline characteristics, mean and standard deviation (SD)

\begin{tabular}{|c|c|c|c|c|c|c|c|c|}
\hline & $C(n=411)$ & PB $(n=439)$ & $\operatorname{PE}(n=435)$ & WB $(n=423)$ & WE $(n=432)$ & $F$ & $x^{2}$ & $P$ \\
\hline Mean age (years)(SD) & $64.2(9.5)$ & $63.1(8.7)$ & $64.0(9.4)$ & $61.8(7.1)$ & $60.8(7.5)$ & 12.05 & & $0.00^{\mathrm{a}}$ \\
\hline Gender (\% men) & 49.9 & 45.9 & 45.3 & 52.3 & 51.3 & & 10.63 & 0.22 \\
\hline Education (\% low) & 50.3 & 43.5 & 47.3 & 46.1 & 47.8 & & 4.04 & 0.40 \\
\hline Paid job (\%) & 42.8 & 40.1 & 43.9 & 36.8 & 40.2 & & 5.14 & 0.27 \\
\hline \multicolumn{9}{|l|}{ Physical activity } \\
\hline MET-hours PA/week (SD) & $45.4(40.0)$ & $41.6(37.7)$ & $41.5(32.1)$ & $42.9(38.9)$ & $43.0(40.7)$ & 0.71 & & 0.58 \\
\hline Minutes MVPA/week (SD) & $806.7(786.8)$ & $741.3(739.1)$ & $711.7(646.7)$ & $684.8(719.9)$ & $733.4(721.0)$ & 1.63 & & 0.16 \\
\hline Days with sufficient PA (SD) & $3.8(2.1)$ & $4.0(2.0)$ & $3.9(2.0)$ & $4.3(2.1)$ & $4.0(1.9)$ & 4.95 & & $0.00^{b}$ \\
\hline Mean utility (SD) & $0.873(0.180)$ & $0.870(0.166)$ & $0.891(0.150)$ & $0.880(0.163)$ & $0.890(0.158)$ & 1.17 & & 0.32 \\
\hline Mean health care costs (SD) & $1012(3751)$ & $713(1568)$ & $625(1532)$ & $733(1372)$ & $686(1907)$ & 1.94 & & $0.10^{c}$ \\
\hline Mean participant and family costs (SD) & $272(624)$ & $352(922)$ & $274(602)$ & $405(1060)$ & $331(1001)$ & 1.78 & & $0.13^{d}$ \\
\hline Mean productivity losses (SD) & $220(2547)$ & $196(1069)$ & 199 (1009) & $465(2758)$ & $309(1694)$ & 1.63 & & 0.17 \\
\hline Mean societal costs (SD) & $1683(4993)$ & $1254(2315)$ & $1083(2001)$ & $1583(3406)$ & $1290(2876)$ & 2.41 & & $0.05^{c}$ \\
\hline
\end{tabular}

NB: all costs are expressed in Euro's.

aPost-hoc analysis revealed significant differences: $C>W B ; C>W E ; P B>W E ; P E>W B ; P E>W E$.

${ }^{b}$ Post-hoc analysis revealed significant differences: $C<W B ; P E<W B$.

${ }^{C}$ Bootstrap analysis revealed significant differences: $C>P E$.

${ }^{\mathrm{d}}$ Bootstrap analysis revealed significant differences: $C<W B ; P E<W B$.

were found for age and days of PA per week. The participants in the control group and PE were significantly older than participants in WB $(p=.001 ; p=.002)$ and $\mathrm{WE}(p=.000 ; p=.000)$; furthermore participants in $\mathrm{PB}$ were significantly older than WE-participants $(p=.001)$. The participants in the control group $(p=.000)$ and PE $(p=.005)$ performed significantly fewer days with sufficient PA at baseline than WB-participants. Bootstrap analyses revealed baseline cost differences for health care costs, participant and family costs and societal costs. Participants in the control group had significantly higher health care (95\% CI: -788 to -37 ) and societal costs (95\% CI: $-1,135$ to -117$)$ at baseline compared to PE-participants. The control group and PE-participants had significantly lower participant and family costs at baseline than WB-participants (95\% CI: 21 to 261).

At the 12-month follow-up, outcome measures were available for 1,235 participants (57.7\%). After imputation, as described in the methods section, outcome measures were available for 2,128 participants (99.4\%) six months after baseline, and for 2,124 participants (99.3\%) at 12month follow-up (see Figure 1).

\section{Costs and effects}

Societal costs after 12 months for the Active Plus intervention as a whole were $€ 2,582$ compared to $€ 2,737$ for the control group. As can be seen in Table 2, societal costs for the different intervention conditions were lowest for $\mathrm{PE}$ with $€ 2,306$, followed by $€ 2,448$ for $\mathrm{PB}, € 2,516$ for WE, $€ 2,737$ for the control group and $€ 3,052$ for WB. Participants in WB had significantly higher productivity losses than participants in the control group and PB (i.e., the bootstrapped 95\% CI did not include zero). No significant differences were found in the other main cost categories. Significant differences in subcategories are marked in Table 2. Intervention costs could not be statistically compared, since there is no variance in these costs within a condition.

Regarding the effects, the Active Plus intervention, as a whole, resulted in a significant increase of 1.5 MET-hours of PA per week $(p=.02)$, compared to a decrease of 2.2 MET-hours of PA per week in the control group. Considering the different intervention conditions, no significant differences were found for MET-hours of PA per week, although the difference between participants in PB and the control group was borderline significant $(p=.067)$.

No significant differences in QALYs were found either in comparing the Active Plus intervention as a whole to the control group, or in comparing the different intervention conditions to each other and the control group (see Table 2).

\section{Cost-effectiveness analyses}

Comparing the costs and effects of the Active Plus intervention as a whole $(N=1,692)$ to the control group $(N=401)$ dominated the control group. Participants in the intervention increased their PA on average 3.8 METhours per week with a cost saving of $€ 174$ per participant (on a yearly basis) compared to the control group. As can be seen in the CEAC in Figure 2, the Active Plus intervention as a whole was preferred over the control group for all WTP thresholds, with a probability of Active Plus being cost-effective of 72 to $99 \%$. 
Table 2 Costs and effectiveness outcomes of the Active Plus intervention conditions at 12 months follow-up

\begin{tabular}{|c|c|c|c|c|c|c|c|c|c|c|c|c|c|c|}
\hline \multirow[b]{2}{*}{ Cost category } & \multirow[b]{2}{*}{$\begin{array}{l}\text { Unit cost } \\
\text { price }^{a}\end{array}$} & \multicolumn{5}{|c|}{ Mean costs (SD) 12 months } & \multicolumn{8}{|l|}{$95 \% \mathrm{Cl}$} \\
\hline & & C & PB & PE & WB & WE & PB-C & PE-C & WB-C & WE-C & PE-PB & WE-WB & PB-WB & PE-WE \\
\hline Intervention costs & - & 0 & 25.77 & 31.21 & 15.53 & 18.83 & - & - & - & - & - & - & - & - \\
\hline Health care costs & & $1682(200)$ & $1423(131)$ & $1320(162)$ & 1437 (129) & 1406 (189) & -739 to 181 & -873 to 122 & -733 to 201 & -813 to 267 & -508 to 315 & -452 to 434 & -372 to 349 & -593 to 397 \\
\hline General practitioner & $29.02^{b}$ & $126(11)$ & $122(7)$ & $117(9)$ & $125(9)$ & $143(11)$ & -29 to 21 & -36 to 18 & -30 to 25 & -13 to 48 & -25 to 17 & -8 to 47 & -25 to 19 & -55 to 1 \\
\hline Life style coach & $27.98^{\mathrm{b}}$ & $16(4)$ & $16(4)$ & $18(5)$ & $20(5)$ & $33(10)$ & -12 to 12 & -12 to 15 & -8 to 18 & -2 to 39 & -11 to 15 & -8 to 35 & -17 to 8 & -38 to 5 \\
\hline Paramedical care & $35.96^{\mathrm{b}}$ & $298(36)$ & $285(34)$ & $191(23)$ & $281(32)$ & $233(32)$ & -111 to 85 & -195 to $-27^{*}$ & -112 to 80 & -158 to 28 & -175 to $-14^{*}$ & -137 to 40 & -87 to 95 & -121 to 36 \\
\hline Mental health care & $82.92^{\mathrm{b}}$ & $48(19)$ & $58(31)$ & $20(7)$ & $67(20)$ & $38(11)$ & -53 to 92 & -72 to 8 & -36 to 72 & -55 to 30 & -112 to 7 & -76 to 14 & -73 to 71 & -43 to 6 \\
\hline Company doctor & $72.48^{c}$ & $15(4)$ & $14(5)$ & $11(4)$ & $23(6)$ & 7 (3) & -13 to 12 & -14 to 7 & -6 to 23 & -18 to 1 & -15 to 9 & -30 to $-3^{*}$ & -25 to 7 & -4 to 14 \\
\hline Social worker & $67.37^{b}$ & $4(2)$ & $10(8)$ & $12(9)$ & $28(14)$ & $5(2)$ & -5 to 25 & -5 to 29 & 1 to $57^{*}$ & -5 to 8 & -20 to 25 & -55 to 1 & -52 to 12 & -7 to 29 \\
\hline Practice nurse & $15.81^{\mathrm{b}}$ & $5(1)$ & $4(2)$ & $10(4)$ & $12(3)$ & $10(2)$ & -4 to 3 & -2 to 15 & 2 to $15^{*}$ & 0 to 10 & -2 to 16 & -12 to 5 & -17 to $-2^{*}$ & -8 to 11 \\
\hline Medical specialist & $74.62^{b}$ & $135(11)$ & $120(11)$ & $130(11)$ & $138(11)$ & $150(14)$ & -44 to 15 & -35 to 27 & -27 to 34 & -18 to 50 & -21 to 41 & -22 to 47 & -48 to 13 & -57 to 15 \\
\hline Hospital admission & $473.65^{b}$ & $418(75)$ & $366(98)$ & $374(114)$ & $291(56)$ & $427(131)$ & -285 to 201 & -288 to 243 & -317 to 52 & -258 to 334 & -281 to 306 & -105 to 444 & -128 to 307 & -401 to 288 \\
\hline Medication & Varying $^{d}$ & $346(56)$ & $271(29)$ & $329(84)$ & $340(70)$ & 308 (98) & -208 to 40 & -195 to 201 & -177 to 184 & -229 to 215 & -84 to 258 & -256 to 229 & -234 to 60 & -249 to 266 \\
\hline Paid homecare & $35.84^{b}$ & 270 (119) & $172(28)$ & $116(28)$ & $99(31)$ & $88(20)$ & -379 to 93 & -428 to 34 & -451 to 19 & -461 to 2 & -134 to 21 & -87 to 59 & -8 to 156 & -39 to 97 \\
\hline Other health care & Varying $^{e}$ & $24(14)$ & $5(2)$ & $5(2)$ & $24(13)$ & $6(2)$ & -51 to 2 & -50 to 2 & -39 to 38 & -50 to 4 & -5 to 5 & -49 to 2 & -50 to 1 & -6 to 4 \\
\hline Participant \& family costs & & $567(47)$ & $604(57)$ & $631(70)$ & $648(68)$ & $585(59)$ & -106 to 187 & -99 to 231 & -76 to 244 & -128 to 169 & -152 to 209 & -243 to 112 & -215 to 120 & -134 to 232 \\
\hline Physical activity costs & - & $371(30)$ & $387(39)$ & $363(33)$ & $349(36)$ & $285(30)$ & -81 to 111 & -94 to 81 & -115 to 75 & -169 to $-1^{*}$ & -126 to 77 & -158 to 27 & -69 to 140 & -8 to 167 \\
\hline Travel costs & Varying $^{b}$ & $75(6)$ & $71(6)$ & $61(5)$ & $79(6)$ & $74(6)$ & -19 to 12 & -28 to 1 & -12 to 21 & -18 to 16 & -25 to 5 & -21 to 13 & -24 to 9 & -29 to 3 \\
\hline Unpaid homecare & $12.80^{\mathrm{b}}$ & $126(32)$ & $155(40)$ & $218(63)$ & $230(57)$ & $235(51)$ & -69 to 135 & -41 to 242 & -16 to 236 & -9 to 229 & -80 to 219 & -154 to 146 & -218 to 54 & -172 to 147 \\
\hline Productivity losses & - & $485(117)$ & $369(118)$ & $296(102)$ & $986(246)$ & $526(159)$ & -443 to 214 & -498 to 113 & 12 to $1068^{*}$ & -334 to 448 & -383 to 230 & -1047 to 99 & -1179 to $-124^{*}$ & -632 to 114 \\
\hline Societal costs & - & 2737 (258) & 2448 (204) & 2306 (223) & 3052 (301) & 2516 (273) & -936 to 345 & -1098 to 235 & -451 to 1090 & -966 to 521 & -737 to 454 & -1338 to 256 & -1339 to 100 & -912 to 444 \\
\hline
\end{tabular}


Table 2 Costs and effectiveness outcomes of the Active Plus intervention conditions at 12 months follow-up (Continued)

\begin{tabular}{|c|c|c|c|c|c|c|c|}
\hline \multirow[b]{2}{*}{ Effectiveness outcomes } & \multicolumn{5}{|c|}{ Mean effects (SD) 12 months } & \multirow[b]{2}{*}{$F$} & \multirow[b]{2}{*}{$P$} \\
\hline & C & PB & $\mathrm{PE}$ & WB & WE & & \\
\hline$\triangle$ MET hours PA/week & $-2.2(29.1)$ & $3.0(28.2)$ & $2.7(27.9)$ & $0.7(27.8)$ & $-0.4(31.6)$ & 2.39 & 0.05 \\
\hline$\Delta$ Minutes MVPA/week & $-72.1(500.9)$ & $3.1(533.8)$ & $37.7(506.1)$ & $-32.8(445.2)$ & $-39.8(522.7)$ & 2.96 & 0.02 \\
\hline$\Delta$ days with sufficient PA & $0.1(1.7)$ & $0.4(1.7)$ & $0.5(1.6)$ & $0.0(1.4)$ & $0.2(1.3)$ & 5.87 & 0.00 \\
\hline QALY-EQ-5D-3L & $0.884(0.164)$ & $0.876(0.155)$ & $0.883(0.160)$ & $0.883(0.162)$ & $0.888(0.165)$ & 0.339 & 0.85 \\
\hline
\end{tabular}

$\mathrm{C}=$ control group, $\mathrm{PB}=$ printed basic intervention, $\mathrm{PE}=$ printed environmental intervention, $\mathrm{WB}=$ Web-based basic intervention, $\mathrm{WE}=$ Web-based environmental intervention.

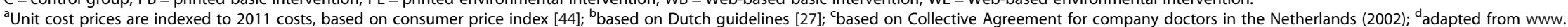

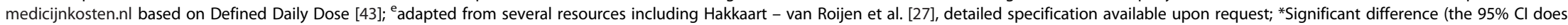
not include zero). 

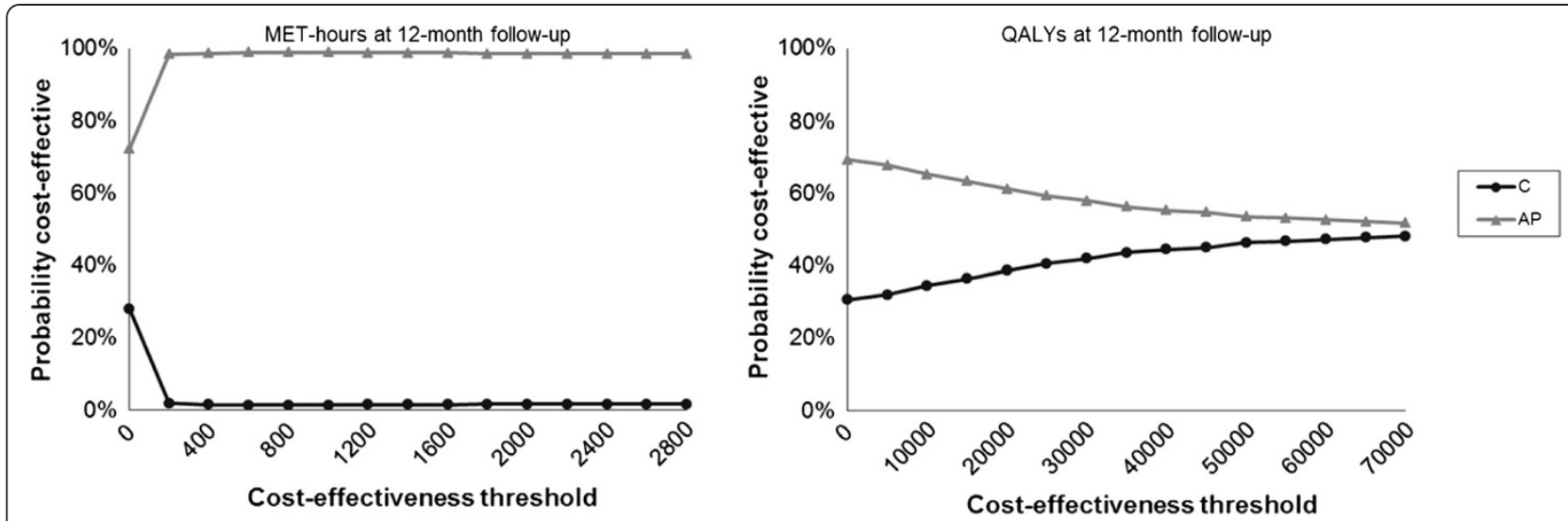

Figure 2 Cost-effectiveness acceptability curves (CEAC) comparing the intervention as a whole (AP) to the control group (C).

Considering the costs and effects of the different intervention conditions $\mathrm{PB}(N=428), \mathrm{PE}(N=421)$ and WE $(N=425)$ all had lower costs and higher effects on MET-hours compared to the control group: all three dominated the control group. ICERs are shown in Table 3. Participants in the PB condition increased their PA with (on average) 5.3 MET-hours/week at a yearly cost saving of $€ 288$ per participant. For PE and WE this was an increase of 5.0 MET-hours/week at a yearly cost saving of $€ 464$ per participant and an increase of 1.8 MET-hours/week at a yearly cost saving of $€ 255$ per participant respectively. The ICER comparing WB $(N=418)$ to the control group indicated that WB had higher costs, but also higher effects than the control group. Participants in this condition increased their PA on average 3.0 MET-hours/week at a yearly cost of $€ 318$ per participant compared to the control group. Whether WB dominates the control group depends on the willingness-to-pay for each additional MET-hour of PA, however, as mentioned in the methods, no WTP for MET-hours is yet available.

When comparing both environmental interventions to both basic interventions, the environmental interventions have lower costs (PE-PB: $€-176$; WE-WB $€ 573$ ) than the basic interventions, but at the expense of lower effects (PE-PB: -0.3 MET-hour/week; WE-WB: -1.1 MET-hours/ week). The preferred intervention therefore depends on the WTP. Both printed interventions (PB and PE) had lower costs and higher effects at the 12-month followup and were thus, dominant over both Web-based interventions (WB and WE). Indicating that participants in the PB condition increased their PA with (on average) 2.3 MET-hours/week at a yearly cost saving of $€ 606$ per

Table 3 Incremental cost-effectiveness (ICER) and cost-utility (ICUR) ratios of the Active Plus intervention conditions

\begin{tabular}{|c|c|c|c|c|c|c|}
\hline & \multicolumn{3}{|c|}{ Cost-effectiveness analysis } & \multicolumn{3}{|l|}{ Cost-utility analysis } \\
\hline & Incremental costs ${ }^{\mathrm{a}, \mathrm{b}}$ & Incremental MET-hours/week & ICER $^{c}$ & Incremental costs ${ }^{\mathrm{a}, \mathrm{b}}$ & Incremental QALYs $^{\mathrm{d}}$ & ICUR $^{c}$ \\
\hline \multicolumn{7}{|l|}{ Intervention vs. control } \\
\hline Intervention as a whole & -174 & 3.8 & $-46^{e}$ & -153 & -0.002 & $101,169^{f}$ \\
\hline PB & -288 & 5.3 & $-55^{\mathrm{e}}$ & -315 & -0.008 & $38,120^{f}$ \\
\hline PE & -464 & 5.0 & $-94^{e}$ & -434 & -0.001 & $405,892^{f}$ \\
\hline WB & 318 & 3.0 & $108^{h}$ & 364 & -0.001 & $440,164^{9}$ \\
\hline WE & -255 & 1.8 & $-139^{e}$ & -211 & 0.004 & $-47,293^{e}$ \\
\hline \multicolumn{7}{|l|}{ Environment vs. basic } \\
\hline PE vs. PB & -176 & -0.3 & $555^{h}$ & -119 & 0.007 & $-16,516^{e}$ \\
\hline WE vs. WB & -573 & -1.1 & $514^{h}$ & -575 & 0.005 & $-108,851^{e}$ \\
\hline \multicolumn{7}{|l|}{ Print vs. Web } \\
\hline PB vs. WB & -606 & 2.3 & $-261^{e}$ & -679 & -0.007 & $91,336^{\mathrm{f}}$ \\
\hline PE vs. WE & -209 & 3.1 & $-67^{e}$ & -223 & -0.006 & $40,426^{\dagger}$ \\
\hline
\end{tabular}

$\mathrm{C}=$ control group, $\mathrm{PB}=$ printed basic intervention, $\mathrm{PE}=$ printed environmental intervention, $\mathrm{WB}=\mathrm{Web}$-based basic intervention, $\mathrm{WE}=\mathrm{Web}-\mathrm{based}$ environmental intervention.

${ }^{a}$ In Euros; ${ }^{b}$ differences in incremental costs for the ICER and ICUR occur due to differences in the number of participants for which MET-hours/week and QALYs were available; ${ }^{c}$ calculated according to the formula ICER (or ICUR) $=\left(\right.$ Costs $_{i}-$ Costs $\left._{c}\right) /\left(\right.$ Effect $_{i}-$ Effect $\left._{c}\right)$; ${ }^{d}$ Based on the Dutch algorithm for the EuroQol $($ EQ-5D-3L) scores; ${ }^{\mathrm{e}}$ dominant; ${ }^{\mathrm{f}}$ dominant based on WTP $=€ 20,000$ (i.e. savings larger than WTP); ${ }^{\text {g }}$ dominated; ${ }^{\mathrm{h}}$ preferred intervention depends on WTP (unknown for PA). 
participant compared to participants in the WB condition. For participants in the PE condition compared to participants in the WE condition this was an increase of 3.1 MET-hours/week at a yearly cost saving of $€ 209$ per participant. The CEAC in Figure 3 demonstrates that $\mathrm{PE}$ was the preferred intervention condition for WTP thresholds below $€ 1,000$ and PB for WTP thresholds higher than $€ 1,000$, with a probability of $50 \%$ to be the most cost-effective alternative.

\section{Cost-utility analyses}

As a whole, the Active Plus intervention $(N=1,662)$ resulted in lower costs (incremental costs $=€-153$ ), but also in fewer QALYs compared to the control group $(N=402$; incremental effects $=-0.002$ QALY), resulting in an ICUR of 101,169 . Because both incremental costs and effects are negative, it might be difficult to interpret the ICUR. In this context the ICUR indicates how much society would save for a decrease of one QALY, thus the ICUR should be at least $€ 20,000$, to have enough savings to compensate for the loss of one QALY. Since the ICUR was higher than the WTP of $€ 20,000$ the Active Plus intervention dominated the control group. Figure 2 showed that, as a whole the Active Plus intervention had a probability of $61 \%$ being cost-effective at a WTP of $€ 20,000$ compared to the control group.

Comparing the different intervention conditions with regard to QALYs indicated that WE $(N=408)$ had higher effects and lower costs and thus dominated the control group. Participants in the WE condition gained 0.004 QALY with a yearly cost saving of $€ 211$ per participant compared to the control group. Although PB $(N=430)$ and PE $(N=418)$, had lower costs (PB-C: $€-315$; PE-C: $€-434)$ at the expense of lower effects (PB-C: -0.008 QALY; PE-C: -0.001 QALY) they still dominated the control group based on a WTP of $€ 20,000$ as cost savings could compensate the decrease in QALYs. WB $(N=406)$ had higher costs (€364) and lower effects (-0.001 QALY) and was thus dominated by the control group.

Comparing the environmental interventions to the basic interventions, PE and WE both had higher effects and lower costs and were thus dominant to $\mathrm{PB}$ and WB. Participants in the PE condition gained (on average) 0.007 QALY at a yearly cost saving of $€ 315$ per participant compared to participants in the PB condition. For participants in the WE condition compared to participants in the WB condition this was a gain of 0.005 QALY at a yearly cost saving of $€ 575$ per participant. Both printed interventions, $\mathrm{PB}$ and $\mathrm{PE}$, had lower effects (PB-WB: -0.007 QALY; PE-WE: -0.006 QALY) and lower costs (PB-WB: $€-679$; PE-WE: $€-223)$, but dominated their Web-based counterparts (WB and WE) based on a WTP of $€ 20,000$. The ICURS are shown in Table 3. PE had the highest probability to be cost-effective for WTP thresholds below $€ 45,000$ as can be seen in Figure 3. At a WTP of $€ 20,000$ the probability of PE being cost-effective was $45 \%$.

\section{Sensitivity analyses}

In the sensitivity analyses for the different intervention conditions, PE is predominantly found to be the dominant intervention condition with probabilities of being costeffective ranging from 38 to $83 \%$ (Table 4). In the primary analysis for PA at the 12-month follow-up, PE was also dominant for lower WTP values, whereas PB was the dominant intervention condition for WTP thresholds above $€ 1,000$ (Table 4). The sensitivity analysis in which a baseline correction was applied and the analysis from a health care perspective showed the same result as the primary analysis. The complete cases analysis showed an almost similar result although at the lowest WTP thresholds (WTP $<€ 50)$ WE was the dominant intervention condition. In the sensitivity analysis with MET-hours of PA per week and costs at the 6-month follow-up, PE turned out to be the most cost-effective intervention condition, as was the case in the sensitivity analyses

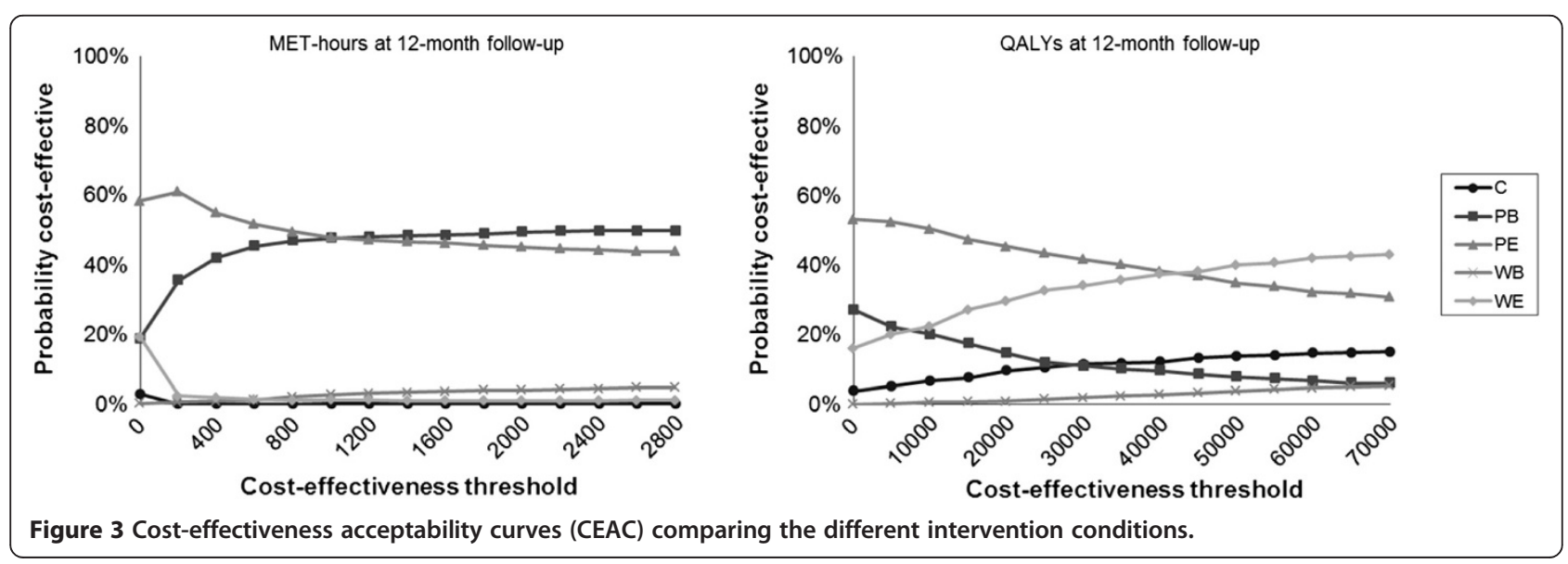


Table 4 Primary and sensitivity analyses of the Active Plus intervention conditions at the 12-month follow-up

\begin{tabular}{|c|c|c|c|c|c|c|c|c|c|c|c|c|}
\hline & \multicolumn{2}{|l|}{$\mathrm{C}$} & \multicolumn{2}{|l|}{ PB } & \multicolumn{2}{|l|}{$\mathrm{PE}$} & \multicolumn{2}{|l|}{ WB } & \multicolumn{2}{|l|}{ WE } & \multirow[t]{2}{*}{ ICER $^{\mathrm{b}}$} & \multirow[t]{2}{*}{ CEAF $^{\mathrm{d}}$ and probability highest NMB } \\
\hline & Costs $^{a}$ & $\overline{\text { Effect }}$ & $\operatorname{Costs}^{a}$ & Effect & Costs $^{\mathrm{a}}$ & $\overline{\text { Effect }}$ & $\operatorname{Costs}^{\mathrm{a}}$ & $\overline{\text { Effect }}$ & $\operatorname{Costs}^{\mathrm{a}}$ & Effect & & \\
\hline \multicolumn{13}{|l|}{ Primary analysis } \\
\hline PA (MET-hours/week) & $2760(5301)$ & -2.2 & $2472(4269)$ & 3.0 & $2295(4694)$ & 2.7 & $3078(6301)$ & 0.7 & $2504(5666)$ & -0.4 & 555 (PE vs PB) & $<€ 1000$ PE, >€1000 PBPB: 50\%; PE: 43\% \\
\hline QALY-EQ-5D-3L & $2739(5293)$ & 0.884 & $2424(4212)$ & 0.876 & $2305(4642)$ & 0.883 & $3103(6378)$ & 0.883 & $2528(5730)$ & 0.888 & 40426 (PE vs WE) & $<€ 40000$ PE, >€40000 WE; PE: 45\% \\
\hline \multicolumn{13}{|l|}{ Sensitivity analyses } \\
\hline \multicolumn{13}{|l|}{ 6-month follow-up } \\
\hline PA (MET-hours/week) & $1444(2988)$ & 7.4 & $1329(2880)$ & 11.5 & $1106(2456)$ & 15.6 & $1501(3207)$ & 13.9 & $1201(2663)$ & 8.1 & PE dominant & PE at any threshold; PE: 74\% \\
\hline QALY-EQ-5D-3L & $1442(2985)$ & 0.442 & $1307(2860)$ & 0.438 & $1106(2426)$ & 0.441 & $1547(3305)$ & 0.442 & $1211(2683)$ & 0.444 & 38110 (PE vs WE) & $<€ 45000 P E_{1}>€ 45000$ WE; PE: 56\% \\
\hline \multicolumn{13}{|l|}{ Complete cases } \\
\hline PA (MET-hours/week) & $2382(3880)$ & -2.5 & $2592(4666)$ & 6.3 & $2316(4986)$ & 5.7 & $2824(5241)$ & 1.7 & $2217(3316)$ & 4.1 & 472 (PE vs PB) & $<€ 50 \mathrm{WE},>€ 50<€ 400 \mathrm{PE},>€ 400 \mathrm{~PB} ; \mathrm{PB}: 44 \%$ \\
\hline QALY-EQ-5D-3L ${ }^{c}$ & $2488(4212)$ & 0.902 & $2423(4452)$ & 0.878 & $2166(4668)$ & 0.898 & $2635(5031)$ & 0.893 & $2198(3774)$ & 0.892 & PE dominant & PE at any threshold; PE: $46 \%$ \\
\hline \multicolumn{13}{|l|}{ Baseline correction } \\
\hline PA (ME- hours/week) & $2862(3742)$ & -2.2 & $2664(3277)$ & 3.0 & $2614(3824)$ & 2.7 & $3038(4593)$ & 0.7 & $2794(4618)$ & -0.5 & 157 (PE vs PB) & $<€ 175$ PE, >€175 PB; PB: 54\% \\
\hline QALY-EQ-5D-3L ${ }^{c}$ & $2851(3737)$ & 0.884 & $2633(3252)$ & 0.876 & $2622(3811)$ & 0.883 & $3045(4643)$ & 0.883 & $2795(4667)$ & 0.888 & 31308 (PE vs WE) & $<€ 30000 P E_{1}>€ 30000$ WE; PE: 38\% \\
\hline \multicolumn{13}{|l|}{ Health care perspective } \\
\hline PA (MET-hours/week) & $1693(4093)$ & -2.2 & $1441(2817)$ & 3.0 & $1297(3340)$ & 2.7 & $1438(2658)$ & 0.7 & 1419 (3963) & -0.4 & 452 (PE vs PB) & $<€ 400 \mathrm{PE},>€ 400 \mathrm{~PB} ; \mathrm{PB}: 53 \%$ \\
\hline QALY-EQ-5D-3L & $1670(4082)$ & 0.884 & $1386(2729)$ & 0.876 & $1287(3256)$ & 0.883 & $1428(2664)$ & 0.883 & $1386(3965)$ & 0.888 & 17966 (PE vs WE) & $<€ 12500 \mathrm{PE},>€ 12500 \mathrm{WE} ; \mathrm{WE}: 42 \%$ \\
\hline \multicolumn{13}{|l|}{ Other outcome measures } \\
\hline Minutes MVPA/week & $2749(5264)$ & -72.1 & $2463(4241)$ & 3.1 & $2306(4696)$ & 37.7 & $3078(6301)$ & -32.8 & $2504(5666)$ & -39.8 & PE dominant & PE at any threshold; PE: 83\% \\
\hline Days with sufficient PA & $2720(5349)$ & 0.1 & $2520(4303)$ & 0.4 & $2341(4740)$ & 0.5 & $3076(6286)$ & 0.0 & $2503(5645)$ & 0.2 & PE dominant & PE at any threshold; PE: 76\% \\
\hline QALY-EQ-5D-3L UK tariff & $2739(5293)$ & 0.858 & $2424(4212)$ & 0.846 & $2305(4642)$ & 0.856 & $3103(6378)$ & 0.857 & $2528(5730)$ & 0.864 & 25001 (PE vs WE) & $<€ 25000 \mathrm{PE},>€ 25000 \mathrm{WE} ; \mathrm{PE}: 42 \%$ \\
\hline
\end{tabular}

$\mathrm{PB}=$ printed basic intervention, $\mathrm{PE}=$ printed environmental intervention, $\mathrm{WB}=$ Web-based basic intervention, $\mathrm{WE}=$ Web-based environmental intervention, $\mathrm{C}=$ control group .

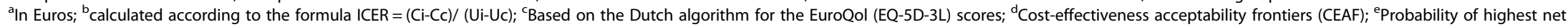

monetary benefit (NMB) based on WTP $=€ 20,000$. 
with regard to different PA outcomes. Sensitivity analyses for QALY were similar to the primary analysis for QALY, with PE being the dominant intervention condition.

Analyses comparing only three groups were done to make some more powerful inferences about preferred delivery mode and the inclusion of environmental information. A printed intervention delivery was found to be the dominant delivery mode in the analyses in which both printed interventions, both Web-based interventions and the control group were compared, with probabilities of 96\% (for MET-hours of PA) and 65\% (for QALYs), as can be seen in Table 5 . Analyses in which the effect of adding environmental were examined revealed that the basic intervention was dominant for MET-hours of PA, whereas the environmental intervention was dominant for QALY outcomes with probabilities of 68\% (MET-hours of PA) and 75\% (QALYs) (see Table 5).

\section{Discussion}

The purpose of the current study was to compare the Active Plus intervention to a control group in terms of cost-effectiveness (MET-hours) and cost-utility (QALYs). Furthermore, the four intervention conditions (i.e., printed basic, printed environmental, Web-based basic, and Web-based environmental) and the control group were compared to each other. To our knowledge, this is the first study comparing the cost-effectiveness and cost-utility of a computer-tailored physical activity advice, delivered either in a printed fashion or via the Internet. Although a number of studies reported comparisons of Webbased interventions with print-delivered interventions, none of these, published information regarding costeffectiveness [2,22].

\section{Cost-effectiveness of the intervention}

The Active Plus intervention was cost-effective as it resulted in lower societal costs and an increase in MET-hours of PA per week compared to the control group. With regard to the cost-effectiveness of the different intervention conditions, it was found that both printed interventions (PB and $\mathrm{PE}$ ), and the Web-based intervention with environmental information (WE) were cost-effective compared to the control group, as all three resulted in lower costs and higher effects. This indicates that the implementation of the intervention in general, and specifically these three intervention conditions requires some upfront investment of money, but even in one year, this already results in cost savings to society (mainly due to decreased health care costs). The basic Web-based intervention (WB) resulted in a higher increase in MET-hours of PA per week compared to the control group, but also in higher societal costs. The cost-effectiveness of the WB intervention condition is thus, dependent on the willingness-to-pay for each additional MET-hour.

Although one might think that a Web-based intervention has the highest potential to be cost-effective compared to a printed intervention, as is also shown in a cost-analysis by Lewis [24], the results from the current study (including a societal perspective, in contrast to Lewis [24]) showed otherwise. Comparing all intervention conditions with each other showed that, although depending on the WTP, both printed interventions had the highest probability

Table 5 Sensitivity analyses comparing 3 groups of the Active Plus intervention at the 12-month follow-up

\begin{tabular}{|c|c|c|c|c|c|c|c|c|}
\hline & \multicolumn{2}{|c|}{ Control group } & \multicolumn{2}{|c|}{$\begin{array}{l}\text { Print-delivered } \\
\text { intervention (PB \& PE) }\end{array}$} & \multicolumn{2}{|c|}{$\begin{array}{l}\text { Web-based intervention } \\
\text { (WB \& WE) }\end{array}$} & \multirow[t]{2}{*}{ ICER $^{b}$} & \multirow[t]{2}{*}{$\begin{array}{l}\text { CEAF }^{d} \text { and probability } \\
\text { highest NMB }\end{array}$} \\
\hline & Costs $^{a}$ & $\overline{\text { Effect }}$ & $\operatorname{Costs}^{a}$ & Effect & Costs $^{a}$ & Effect & & \\
\hline \multirow{2}{*}{$\begin{array}{l}\text { PA (MET } \\
\text { hours/week) }\end{array}$} & \multirow[t]{2}{*}{$2760(5301)$} & \multirow[t]{2}{*}{-2.2} & \multirow[t]{2}{*}{2384 (4483) } & \multirow[t]{2}{*}{2.9} & \multirow[t]{2}{*}{2789 (5992) } & \multirow[t]{2}{*}{0.2} & \multirow[t]{2}{*}{ Print dominant } & Print at any threshold \\
\hline & & & & & & & & Print: $96 \%$ \\
\hline \multirow[t]{4}{*}{ QALY-EQ-5D-3L ${ }^{\mathrm{C}}$} & \multirow[t]{2}{*}{2739 (5293) } & \multirow[t]{2}{*}{0.884} & \multirow[t]{2}{*}{$2365(4427)$} & \multirow[t]{2}{*}{0.879} & \multirow[t]{2}{*}{$2800(6054)$} & \multirow[t]{2}{*}{0.886} & \multirow[t]{2}{*}{79196 (Print vs. C) } & $<€ 65000$ Print, $>€ 65000 C$ \\
\hline & & & & & & & & Print: $65 \%$ \\
\hline & \multicolumn{2}{|c|}{ Control group } & \multicolumn{2}{|c|}{$\begin{array}{l}\text { Basic intervention } \\
\text { (PB \& WB) }\end{array}$} & \multicolumn{2}{|c|}{$\begin{array}{l}\text { Environmental } \\
\text { intervention (PE \& WE) }\end{array}$} & \multirow[t]{2}{*}{ ICER $^{\mathbf{b}}$} & \multirow[t]{2}{*}{$\begin{array}{l}\text { CEAF }^{d} \text { and probability } \\
\text { highest NMB }\end{array}$} \\
\hline & Costs $^{a}$ & Effect & Costs $^{\mathrm{a}}$ & Effect & Costs $^{a}$ & Effect & & \\
\hline \multirow[t]{2}{*}{$\begin{array}{l}\text { PA (MET } \\
\text { hours/week) }\end{array}$} & \multirow[t]{2}{*}{$2760(5301)$} & \multirow[t]{2}{*}{-2.2} & \multirow[t]{2}{*}{$2771(5375)$} & \multirow[t]{2}{*}{1.9} & \multirow[t]{2}{*}{$2400(5203)$} & \multirow[t]{2}{*}{1.2} & \multirow[t]{2}{*}{503 (Environment vs. Basic) } & $\begin{array}{l}<€ 550 \text { Environment, } \\
>€ 550 \text { Basic }\end{array}$ \\
\hline & & & & & & & & Basic: 68\% \\
\hline \multirow[t]{2}{*}{ QALY-EQ-5D-3L ${ }^{c}$} & \multirow[t]{2}{*}{2739 (5293) } & \multirow[t]{2}{*}{0.884} & \multirow[t]{2}{*}{$2754(5381)$} & \multirow[t]{2}{*}{0.879} & $2415(5206)$ & 0.886 & Environment dominant & $\begin{array}{l}\text { Environment at } \\
\text { any threshold }\end{array}$ \\
\hline & & & & & & & & Environment: 75\% \\
\hline
\end{tabular}

$\mathrm{PB}=$ printed basic intervention, $\mathrm{PE}=$ printed environmental intervention, $\mathrm{WB}=$ Web-based basic intervention, $\mathrm{WE}=\mathrm{Web}$-based environmental intervention, $\mathrm{C}=$ control group.

${ }^{a}$ In Euros; ${ }^{b}$ calculated according to the formula ICER $=(\mathrm{Ci}-\mathrm{Cc}) /(\mathrm{Ui}-\mathrm{Uc}) ;{ }^{\mathrm{c} B a s e d}$ on the Dutch algorithm for the EuroQol (EQ-5D-3L) scores; ${ }^{\mathrm{d}} \mathrm{Cost}-\mathrm{effectiveness}$

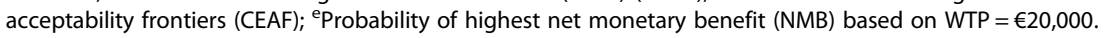


of being cost-effective despite the fact that they have the highest intervention costs. The high probability of cost-effectiveness of these intervention conditions might be explained by the fact that these conditions resulted in the highest intervention effects, which might have resulted in savings in health care costs and thereby lower societal costs. Previous research has also shown that changes in PA result in decreased health care charges in the short term. [14] The lower effects of the Web-based intervention conditions can also be explained by the lower use of several intervention components [30] and the higher dropout within the intervention period when compared to the printed intervention [28]. Furthermore, costs from productivity losses (i.e., sick leave) were highest in the Web-based conditions (significantly in WB), resulting in higher societal costs and thus, less positive cost-effectiveness ratios, which might be explained by the fact that different kinds of people respond to the different types of interventions. For example, people participating in the Web-based intervention were significantly younger than participants of the printed intervention. The (younger) Web-based participants were thereby more likely to spend more hours at work than the printed intervention participants, resulting in a higher susceptibility for sick leave, and thus higher potential productivity losses.

As mentioned above, the preferred intervention depends on the WTP. PE had the highest probability of being cost-effective for WTP-thresholds up to $€ 1,000 / \mathrm{MET}$ hour, whereas PB had the highest probability of being cost-effective for thresholds above $€ 1,000 / M E T-h o u r$. This turning point can be explained by the fact that $\mathrm{PB}$ had the highest effects and PE the lowest societal costs, thus, if society is willing to pay more for an additional MET-hour, PB becomes the preferred intervention as it results in higher effects. Determining which intervention condition is most cost-effective is difficult as there is currently no information about how much society is willing to pay for an additional MET-hour, as it is unclear for other health behaviour outcomes [31,41,42]. Therefore, it is desirable if future research is aimed at identifying maximum WTP thresholds for health behaviours.

Several reviews described the cost-effectiveness of PA interventions; however the majority of the included studies were not conducted from a societal perspective $[9,49]$. The only study conducted from a societal perspective reported an ICER of $€ 825$ for one inactive participant to become norm active [50], i.e., an increase of 10 METhours [11]. The Active Plus intervention in general and specifically the $\mathrm{PB}, \mathrm{PE}$ and WE conditions were obviously more cost-effective than the intervention reported by Elley et al. [50], since they would result in cost savings. The costs of the WB condition for getting an inactive participant to become norm active would be (10 times $€ 108 /$ MET-hour) $€ 1,008$, which is higher than that reported by
Elley et al. [50]. However, the Active Plus study population includes both inactive as well as norm-active participants and is not specifically targeted for an inactive population. A meta-analysis by Woodcock et al. [12] showed that the largest health gains (and thus the largest health care cost savings) occur for the first 15-29 PA-minutes per day by inactive people. This would indicate that if the Active Plus intervention was only implemented in an inactive population, Active Plus would result in even larger health effects, and the ICER would probably be lower than reported in this study, making the WB condition comparably costeffective to the intervention reported in the study by Elley et al, and the PB, PE and WE condition even more costeffective than the intervention by Elley et al. [50]. Further research should provide insight in the differences in costeffectiveness of the intervention in inactive populations when compared to the population in general.

\section{Cost-utility of the intervention}

Assessing cost-effectiveness in terms of QALYs allows for comparing interventions aimed at different health behaviors. Results showed that although, compared to the control group, PA increased more in the Active Plus intervention as a whole, this was not reflected in more QALYs. Nevertheless, the Active Plus intervention had the highest probability of being cost-effective for WTPthresholds up to $€ 70,000$, since it results in savings of societal costs. With regard to the different intervention conditions, $\mathrm{PB}, \mathrm{PE}$ and WE were found to be cost-effective when considering a WTP of $€ 20,000 / \mathrm{QALY}$. PE had the highest probability $(45 \%)$ to be cost-effective at a WTP of $€ 20,000 / \mathrm{QALY}$. Although there is a WTP available for QALYs [46,47], making it possible to draw conclusions on cost-effectiveness, differences in QALYs were very small (i.e., the largest observation was an effect of -.008), insignificant and clinically irrelevant, making it difficult to draw conclusions. However, the size of the effect was comparable with other studies with the same time frame [51]; a positive relationship between PA and quality of life is often not found in longitudinal research [52,53]. It is assumed that most health benefits of PA that are reflected in quality of life only become visible when follow-up time increases (beyond the trial period). Since such a long follow-up period is often unfeasible, modeling cost-effectiveness to increase the time horizon is recommended [54]. Furthermore, according to the Set-Point Model, it is assumed that quality of life is quite stable, and only varies temporarily from a certain baseline level in major life events $[18,55,56]$, and according to the Response Shift Theory, participants may have adapted to the new situation [57]. A third possible reason for not detecting substantial differences in QALYs might be the generic measure used in the current study. It is known that the EuroQol is not sensitive enough to detect 
changes in quality of life in relatively healthy populations such as the participants of the Active Plus intervention [58]. The development of a measure that is more sensitive to changes in a healthy population is necessary, allowing for cost-utility analyses in future economic evaluations of public health interventions $[59,60]$.

\section{Sensitivity analyses}

Although there were some differences from the main analysis with regard to probability of being cost-effective, in most cases PE had the highest probability of being cost-effective at lower WTP values, indicating that results are robust. In the case that intervention maintenance is optimised (first sensitivity analysis), PE still had the highest probability of being cost-effective.

In the primary analysis an imputed dataset was used for increased power. Since fairly similar results were found for the complete case analysis (both for PA and QALYs) it seems that the results are robust for the methods used to impute incomplete data.

Sensitivity analyses were performed with three groups (the control group, both printed interventions together and both Web-based interventions together) to make more powerful inferences about the preferred delivery mode and the addition of environmental information. Results indicated that a printed intervention was preferred. With regard to adding environmental information, results were less clear. For PA outcomes adding environmental information was preferred at lower WTP thresholds, whereas a basic intervention was most cost-effective at higher WTP thresholds. With regard to QALYs an environmental intervention was preferred; this is in line with $\mathrm{PE}$ being the most cost-effective intervention condition at the lower WTP thresholds.

\section{Strengths and limitations}

Although the results from this study come from a strong (societal) perspective, the current study has some limitations that should be noticed. One of these limitations is the high number of participants dropping-out of the study and the associated missing values. However, the drop-out rate in the current study is comparable with other studies $[22,41,42]$. Furthermore, missing values were imputed conservatively (i.e., the PA effect of non-responding participants was assumed to be equal to the control group). This is more conservative than applying multiple imputation, since multiple imputation might overestimate intervention effects [61].

Furthermore, self-reported measurements were used, which can result in measurement bias in the form of social desirable answers and recall bias. However, no differences in measurement or recall bias were expected between the groups. For PA, self-administered questionnaires are the most commonly used, as this is the most inexpensive method to use in large-scale studies. However, validating the intervention effects with an objective measure (e.g., an accelerometer) is recommended.

Despite these limitations, to our current knowledge this is the first study comparing the cost-effectiveness and cost-utility of a computer-tailored physical activity advice, delivered either in a printed fashion or via the Internet. This economic evaluation, in contrast to most other studies $[9,49]$, is carried out from a strong study design, including longitudinal observations and a societal perspective, needed to get a complete description of costs and benefits [26]. Other strengths include the randomised controlled trial $[62,63]$ and the large study population of more than 2,100 participants.

\section{Conclusion}

From the current study it can be concluded that a tailored PA intervention is a cost-effective strategy to promote PA behaviour in adults aged over fifty. Specifically, the printed basic, the printed environmental and the Webbased environmental condition were cost effective tailoring strategies since these resulted in increased PA behaviour and lower societal costs (mainly due to decreased health care costs). Printed and Web-based tailoring interventions to promote PA behaviour in adults aged over fifty can thus, contribute to individual health and thereby also to public health by increasing PA against acceptable costs.

\section{Additional file}

Additional file 1: Specification of intervention costs. This file gives a detailed specification of the intervention costs.

\section{Abbreviations \\ 95\% Cl: 95\% Confidence interval; ANOVA: Univariate one-way analyses of variance; AP: Active plus; C: Control group; CEAC: Cost-effectiveness acceptability curve; CEAF: Cost-effectiveness acceptability frontiers; ICER: Cost-effectiveness ratio; ICUR: Cost-utility ratio; LOCF: Last observation carried forward; MHC: Municipal 'health council; MVPA: Moderate to vigorous physical activity; NICE: National Institute for Health and Clinical Excellence; NMB: Net monetary benefit; PA: Physical activity; PB: Print-delivered basic intervention condition; PE: Print-delivered environmental intervention condition; QALY: Quality adjusted life years; SD: Standard deviation; SQUASH: Short questionnaire to assess health enhancing physical activity; WB: Web-based basic intervention condition; WE: Web-based environmental intervention condition; WTP: Willingness to pay.}

\section{Competing interests}

Hein de Vries is scientific director of Vision2Health, a company that licenses evidence-based innovative computer-tailored health communication tools.

\section{Authors' contributions}

RG and DP gathered the data for the current study. RG performed the analyses and wrote the first draft of the manuscript. DP helped to draft the manuscript. The process was supervised by LL, CB, HV, AM and SE. Special expertise regarding cost-effectiveness analyses was provided by SE. All authors read, modified and approved the final manuscript.

\section{Acknowledgements}

This study was funded by The Netherlands Organization for Health Research and Development (ZonMw, 200110006). 


\section{Author details}

${ }^{1}$ Department of Psychology and Educational Sciences, Open University of the Netherlands, Heerlen, PO Box 2960, 6401 DL Heerlen, The Netherlands. ${ }^{2}$ Caphri School of Public Health and Primary Care, Maastricht University, Maastricht, The Netherlands. ${ }^{3}$ Department of Health Services Research, Maastricht University, Maastricht, The Netherlands. ${ }^{4}$ Trimbos Institute, Netherlands Institute of Mental Health and Addiction, Utrecht, The Netherlands. ${ }^{5}$ Department of Health Promotion, Maastricht University, Maastricht, The Netherlands.

Received: 25 March 2014 Accepted: 19 September 2014

Published online: 28 September 2014

\section{References}

1. World Health Organisation: Global recommendations on physical activity for health. In Global recommendations on physical activity for health. Geneva: World Health Organisation; 2010.

2. Hobbs N, Godfrey A, Lara J, Errington L, Meyer TD, Rochester L, White M Methers JC, Sniehotta FF: Are behavioural interventions effective in increasing physical activity at 12 to 36 months in adults aged 55 to 70 years? A systematic review and meta-analysis. BMC Medicine 2013, 11:75

3. Lee IM, Shiroma EJ, Lobelo F, Puska P, Blair SN, Katzmarzyk PT: Effect of physical inactivity on major non-communicable diseases worldwide: an analysis of burden of disease and life expectancy. Lancet 2012, 380:219-229.

4. Europe WHO: Steps to health: a european framework to promote physical activity for health. Europe: WHO; 2007.

5. Hagberg L: Cost-effectiveness of the promotion of physical activity in health care. Umea: Umea University, Department of Public Health and Clinical Medicine; 2007.

6. Oldridge NB: Economic burden of physical inactivity: healthcare costs associated with cardiovascular disease. Eur J Cardiovasc Prev Rehabil 2008, 15:130-139

7. Colman R, Walker S: The cost of physical inactivity in British Columbia. In Genuine Progress Index for Atlantic Canada - Measuring sustainable development. Glen Haven: Ministry of Health Planning; 2004.

8. Sevick MA, Dunn AL, Morrow MS, Marcus BH, Chen GJ, Blair SN: Costeffectiveness of lifestyle and structured exercise interventions in sedentary adults. Results from project ACTIVE. Am J Prev Med 2000, 19:1-8.

9. Garrett S, Elley CR, Rose SB, O'Dea D, Lawton BA, Dowell AC: Are physical activity interventions in primary care and the community cost-effective? A systematic review of the evidence. Br J Gen Pract 2011, 61:e125-133.

10. Department of Health: At least five a week: Evidence on the impact of physical activity and its relationship to health. London: Department of Health; 2004.

11. Hallal PC, Andersen LB, Bull FC, Guthold R, Haskell W, Ekelund U: Global physical activity levels: surveillance progress, pitfalls, and prospects. Lancet 2012, 380:247-257.

12. Woodcock J, Franco OH, Orsini N, Roberts I: Non-vigorous physical activity and all-cause mortality: systematic review and meta-analysis of cohort studies. Int J Epidemiol 2011, 40:121-138.

13. De Jong A, Van Duin C: Regionale prognose 2009-2040: Vergrijzing en omslag van groei naar krimp. Heerlen: Centraal Bureau voor de Statistiek; 2010.

14. Martinson BC, Crain AL, Pronk NP, O'conner PJ, Maciosek MV: Changes in physical activity and short-term changes in health care charges: a prospective cohort study of older adults. Prev Med 2003, 37:319-326

15. Noar SM, Benac CN, Harris MS: Does tailoring matter? Meta-analytic review of tailored print health behavior change interventions. Psychol Bull 2007, 133:673-693.

16. Krebs P, Prochaska JO, Rossi JS: A meta-analysis of computer-tailored interventions for health behaviour change. Prev Med 2010, 51:214-221.

17. Peels DA, Bolman C, Golsteijn RHJ, De Vries H, Mudde AN, Van Stralen MM, Lechner L: Long-term efficacy of a tailored physical activity intervention among older adults. Int J Behav Nutr Phys Act 2013, 10:104

18. Van Keulen H, Bosman J, van Tulder M, Severens J, de Vries H, Brug J, Mesters I: Cost-effectiveness of tailored print communication, telephone motivational interviewing, and a combination of the two: results of an economic evaluation alongside the Vitalum randomized controlled trial. Int J Behav Nutr Phys Act 2010, 7:64.

19. Van Stralen MM, De Vries H, Mudde AN, Bolman C, Lechner L: The Long-Term Efficacy of Two Computer-Tailored Physical Activity Interventions for Older Adults: Main Effects and Mediators. Health Psychol 2011, 30:442-452.

20. Van Stralen MM, Kok G, De Vries H, Mudde AN, Bolman C, Lechner L: The Active Plus protocol: systematic development of two theory and evidence-based tailored physical activity interventions for the over-fifties. BMC Public Health 2008, 8:399.

21. Peels DA, Van Stralen MM, Bolman C, Golsteijn RHJ, De Vries H, Mudde AN, Lechner L: The Development of a Web-Based Computer Tailored Advice to Promote Physical Activity Among People Older Than 50 Years. J Med Internet Res 2012, 14:e39.

22. Joseph RP, Durant NH, Benitez TJ, Pekmezi DW: Internet-based Physical Activity Interventions. Am J Lifestyle Med 2014, 8:42.

23. Tate DF, Finkelstein EA, Khavjou O: Cost effectiveness of internet interventions: review and recommendations. Ann Behav Med 2009, 38:40-45.

24. Lewis B, Williams D, Neighbors C, Jakicic J, Marcus B: Cost analysis of internet vs. print interventions for physical activity promotion. Psychol Sport Exerc 2010, 11:246-249.

25. Sevick MA, Napolitano MA, Papandonatos GD, Gordon AJ, Reiser LM, Marcus $\mathrm{BH}$ : Cost-effectiveness of alternative approaches for motivating activity in sedentary adults: results of Project STRIDE. Prev Med 2007, 45:54-61.

26. De Salazar L, Jackson S, Shiell A, Rice M: Guide to Economic Evaluation in Health Promotion. Washington D.C: Pan American Health Organization; 2007.

27. Hakkaart-van Roijen L, Tan S, Bouwmans C: Handleiding voor kostenonderzoek: Methoden en standaard kostprijzen voor economische evaluaties in de gezondheidszorg (in Dutch). Rotterdam: College voor Zorgverzekeringen; 2010.

28. Peels DA, Bolman C, Golsteijn RHJ, De Vries H, Mudde AN, Van Stralen MM, Lechner L: Differences in Reach and Attrition between Web-based or Print-delivered Tailored Interventions among Adults aged over Fifty. J Med Internet Res 2012, 14:e179.

29. Van Stralen MM, De Vries H, Mudde AN, Bolman C, Lechner L: The working mechanisms for an environmentally tailored physical activity intervention for older adults: a randomized controlled trial. Int J Behav Nutr Phys Act 2009, 6:83.

30. Peels DA, De Vries H, Bolman C, Golsteijn RHJ, Van Stralen MM, Mudde AN Lechner L: Differences in the use and appreciation of a Web-based or printed computer tailored physical activity intervention for people aged over fifty. Health Educ Res 2013, 28:715-731.

31. Berndt NC: Smoking cessation in patients with coronary heart disease: Determinants of quitting and comparison of the (cost)effectiveness and feasibility of a telephone and face-to-face counseling intervention. Heerlen: Open University, Department of Psychology; 2013.

32. Drummond MF, O'Brien BJ, Sculpher MJ, Thorrance GW, Stoddart GL: Methods for the economic evaluation of health care programmes. Oxford: Oxford University Press; 2005

33. Glick HA, Doshi JA, Sonnad SS, Polsky D: Economic Evaluations in Clinical Trials. Oxford: Oxford University Press; 2007.

34. De Wit GA, Tariq L, Van Gils PF, Panneman M: Over euro en effect: handleiding voor economisch evaluatieonderzoek bij gezondheidsbevordering (in Dutch). Amsterdam: Consument en Veiligheid; 2010.

35. Thorn JC, Coast J, Cohen D, Hollingworth W, Knapp M, Noble SM, Ridyard C, Wordsworth S, Hughes D: Resource-use measurement based on patient recall: Issues and challenges for economic evaluation. Appl Health Econ Health Policy 2013, 11:155-161.

36. Wendel-Vos GCW, Schuit AJ, Saris WH, Kromhout D: Reproducibility and relative validity of the short questionnaire to assess health-enhancing physical activity. J Clin Epidemiol 2003, 56:1163-1169.

37. Wagenmakers R, Van den Akker-Scheek I, Groothoff JW, Zijlstra W, Bulstra SK, Kootstra JWJ, Wendel-Vos W, van Raaij JJAM, Stevens M: Reliability and validity of the short questionnaire to assess health-enhancing physical actiivty (SQUASH) in patients after total hip arthroplasty. BMC Muskuloskeletal Disord 2008, 9:141.

38. EuroQol-group: EuroQol- a new facility for the measurement of health-related quality of life. Health Policy 1990, 16:199-208.

39. Sculpher MJ: NICE's 2008 Methods Guide: sensible concolidation or opportunities missed? Pharmacoeconomics 2008, 26:721-724

40. Lamers LM, McDonnell J, Stalmeier PF, Krabbe PF, Busschbach JJ: The Dutch tariff: results and arguments for an effective design for national EQ-5D valuation studies. Health Econ 2006, 15:1121-1132.

41. Smit ES, Evers SMAA, De Vries H, Hoving C: Cost-effectiveness and cost-utility of internet-based computer tailoring for smoking cessation. J Med Internet Res 2013, 15:e57.

42. Van Wier MF, Dekkers JC, Bosmans JE, Heymans MW, Hendriksen IJM, Pronk NP, Van Mechelen W, Van Tulder MW: Economic evaluation of a weight control program with e-mail and telephone counseling among overweight 
employees: a randomized controlled trial. Int J Behav Nutr Phys Act 2012,

9:112.

43. CVZ: Diemen: College voor Zorgverzekeringen; 2013. www.medicijnkosten.nl.

44. Statline. [http://statline.cbs.nl/statweb]

45. van Asselt AD, van Mastrigt GA, Dirksen CD, Arntz A, Severens JL, Kessels AG: How to deal with cost differences at baseline. Pharmacoeconomics 2009, 27:519-528.

46. RVZ: Zinnige en duurzame zorg: transparante keuzen in de zorg voor een houdbaar zorgstelsel. Zoetermeer: Raad voor de Volksgezondheid en Zorg; 2006.

47. Boersma C, Broere A, Postma M: Quantification of the potential impact of cost-effectiveness thresholds on dutch drug expenditures using retrospective analysis. Value Health 2010, 13:853-856.

48. Dolan P: Modeling vaulations for EuroQol health states. Med Care 1997, 35:1095-1108.

49. Muller-Riemenschneider F, Reinhold T, Willich S: Cost-effectiveness of interventions promoting physical activity. Br J Sports Med 2009, 43:70-76.

50. Elley R, Kerse N, Arroll B, Swinburn B, Ashton T, Robinson E: Costeffectiveness of physical activity counseling in general practice. $N Z$ Med J 2004, 117:U1216.

51. Eriksson MK, Hagberg L, Lindholm L, Malmgren-Olssen EB, Osterlind J, Eliasson M: Quality of life and cost-effectiveness of a 3 year trial of lifestyle intervention in primary health care. Arch Intern Med 2010, 170:1470-1479.

52. Bize R, Johnson JA, Plotnikoff RC: Physical activity level and health-related quality of life in general adult population: a systematic review. Prev Med 2007, 45:401-415.

53. Wendel-Vos GCW, Schuit AJ, Tijhuis MAR, Kromhout D: Leisure time physical activity and health-related quality of life: cross-sectional and longitudinal associations. Qual Life Res 2004, 13:667-677.

54. Kuntz K, Weinstein M: Modelling in economic evaluation. In Economic evaluation in health care: merging theory with practice. Edited by Drummond MF, McGuire A. New York: Oxford university press; 2010.

55. Lucas RE: Adaptation and the set-point model of subjective well-being Does happiness change after major life events? Curr Dir Psychol Sci 2007, 16:75-79.

56. Diener E, Lucas RE, Scollon CN: Beyond the hedonic treadmill: revising the adaptation theory of well-being. Am Psychol 2006, 61:305-314.

57. Sprangers $M$, Schwartz C: Integrating response shift into health-related quality of life research: a theoretical model. Soc Sci Med 1999, 48:1507-1515

58. Kopec JA, Willison KD: A comparative review of four preference-weighted measures of health-related quality of life. J Clin Epidemiol 2003, 56:317-325.

59. Lorgelly PK, Lawson KD, Fenwick EA, Briggs AH: Outcome measurement in economic evaluation of public health interventions: a role for the capability approach? Int J Environ Res Public Health 2010, 7:2274-2289.

60. Herdman M, Gudex C, Lloyd A, Janssen MF, Kind P, Parkin D, Bonsel G, Badia X: Development and preliminary testing of the new five-level version of EQ-5D (EQ-5D-5 L). Qual Life Res 2011, 20:1727-1736.

61. Lee KJ, Simpson JA: Introduction to multiple imputation for dealing with missing data. Respirology 2014, 19:162-167.

62. Flay BR: Efficacy and effectiveness trials (and other phases of research) in the development of health promotion programs. Prev Med 1986, 15:451-474.

63. Flay BR, Biglan A, Boruch RF, Castro FG, Gottfredson D, Kellam S, Moscicki EK, Schinke S, Valentine JC, Ji P: Standards of Evidence: Criteria for efficacy, effectiveness and dissemination. Prev Sci 2005, 6:151-175.

doi:10.1186/s12966-014-0122-z

Cite this article as: Golsteijn et al: Cost-effectiveness and cost-utility of a Web-based or print-delivered tailored intervention to promote physical activity among adults aged over fifty: an economic evaluation of the Active Plus intervention. International Journal of Behavioral Nutrition and Physical Activity 2014 11:122.

\section{Submit your next manuscript to BioMed Central and take full advantage of:}

- Convenient online submission

- Thorough peer review

- No space constraints or color figure charges

- Immediate publication on acceptance

- Inclusion in PubMed, CAS, Scopus and Google Scholar

- Research which is freely available for redistribution

Submit your manuscript at www.biomedcentral.com/submit
Ciomed Central 